\title{
Critical Care In The Air - When Seconds Matter Airmed South Texas
}

\author{
Jonathan Allua ${ }^{1}$ \\ ${ }^{1}$ EMS Operations, Hidalgo County EMS, and AirMed South Texas, Edinburg, Texas, USA \\ E-mail: jallua@hidalgocountyems.org
}

Received 12/17/2020

Accepted for publication 01/08/2021

Published 03/05/2021

Keywords: Trauma; Injury; Emergency; Helicopter; Critical care

There are a "few" adages in emergency medicine, "time is muscle" referring to a heart attack, "time is brain" referring to a stroke, and the pinnacle, "the golden hour" referring to a trauma patient, and the importance of reaching a trauma facility within the first hour from injury. What do they all have in common? They all specify that time is of the essence.

AirMed 1 is a medical helicopter serving the Rio Grande Valley (RGV; Figure 1). Cruising at $155 \mathrm{mph}$, AirMed 1 can rendezvous with EMS units and transport to the hospital in a fraction of the time it would take by ambulance. For example, traveling from Edcouch to DHR Health by ambulance takes an estimated 30 minutes.

AirMed 1 can make the trip in only 6 minutes. The same is true for most of the region where the helicopter can transport to the tertiary care center more rapidly compared to ambulance transport saving valuable minutes that could impact a patient's

clinical outcome.

AirMed 1 is not only a fast ride, but it is also the biggest benefit bringing the critical care transport team directly to the patient. Staffed with a Critical Care Transport Nurse and Critical Care Transport Paramedic, the team brings an advanced level of knowledge, training, and equipment to complement the care being provided by the EMS crew. For example, blood loss is one of the biggest threats to a trauma patient in the field. To combat this, AirMed 1 carries whole blood and liquid plasma on every flight. The ability to replace blood loss with whole blood rather than just IV fluids alone significantly increases a patient's chances of survival.AirMed 1 also transports patients from one facility to another. Often, patients are diagnosed with a life-threatening condition requiring specialized care that is provided at another facility. This results in an interfacility transfer. The Critical Care Transport Team has the capabilities and equipment required to continue the level of care initiated at the sending facility while simultaneously initiating care that will be provided at the receiving facility.

AirMed 1 is a valuable resource available to the entire $\mathrm{RGV}$. Our mission is to provide the residents and visitors of the region with the highest quality and most advanced clinical care available. Our goal is to be a partner with every EMS, Fire Department, Law Enforcement Agency, and Healthcare facility in the region to assist with the care and transport of your most critical patients.

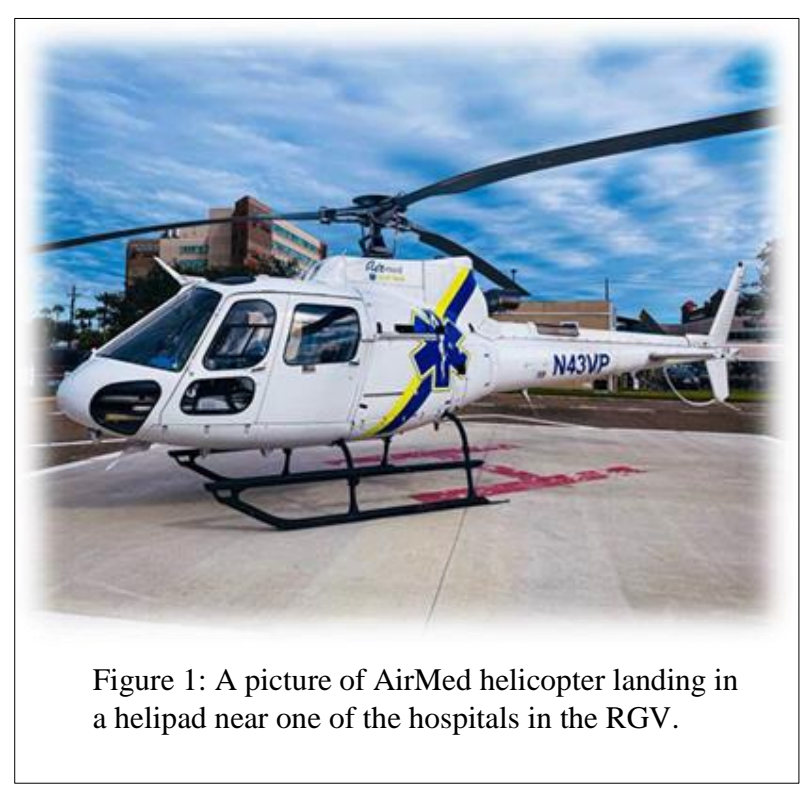




\section{Diclosures}

Author's professional qualifications: RN, LP, CCRN, CFRN, CMTE. JA is the Chief of EMS Operations and Chief Flight Nurse for Hidalgo County EMS \& AirMed South Texas.

\section{References}

No references were used in this document.

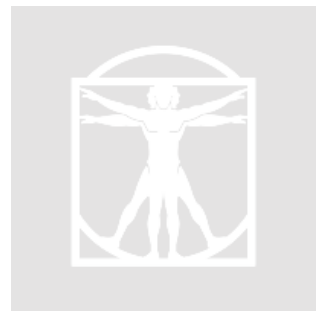

